\title{
INVESTIGATION OF MECHANICAL STRESSES IN THE DRIVE SHAFT OF MV VACUUM CIRCUIT BREAKER
}

\begin{abstract}
Introduction. In the last 10-15 years a dominant position in the market of medium voltage circuit breakers, vacuum circuit breakers have taken in which as an actuator mono- or bistable actuators with permanent magnets are used. Such circuit breakers are characterized by simplicity of design, high reliability, require preventive maintenance for many years. Development, research and improvement of vacuum circuit breakers are carried out at the Department for Electrical Apparatus, National Technical University "Kharkiv Polytechnic Institute». While working on the circuit breakers, developers have to deal with two related objectives - electrical and mechanical. This paper considers the solution of one of these problems - calculation of mechanical forces in the drive shaft of the vacuum circuit breaker in static and dynamic modes. This work was preceded by the failure of the results of measurements of the prototype circuit breakers' contacts. Measurements have shown that these values do not match the expected values (there were less than the value of 0.8 to $1 \mathrm{~mm}$ ). The assumption about the reasons for this discrepancy needed to be detailed checked. The results of the work done are presented in this paper. Purpose. Investigation of static and dynamic mechanical stresses and strains in the drive shaft of the vacuum circuit breaker mechanism to determine its characteristics and material selection. Methods. The investigation of mechanical processes is performed by the finite element method in the COMSOL software package. Results. We obtain the static and dynamic characteristics of the circuit breaker drive shaft: deformations, reaction forces, stresses. These characteristics made it possible to determine the actual course of the contacts, select shaft material and calculate the forces acting on the bearings. Conclusions. It is shown that the contact velocity and contact pressure are different from the theoretical value due to the deformation of the shaft. The forces acting on the thrust bearings dynamically are by 16-39\% higher than the static ones. It is assumed that further refinement of the mathematical model takes into account the traction insulators and housing, as well as dynamics of the circuit breaker. References 19, figures 12.

Key words: vacuum circuit breakers, mechanical calculations, shaft deformation.
\end{abstract}

В статье исследуются процессы, которые определяют механические напряжения в приводном вале вакуумного выключателя в статическом и динамическом режимах работы. Показано, что механическая деформация вала вызывает уменьшение провала контактов на величину до 30\% и сил контактного нажатия на (10-11)\%, эти значения не критичны и мало влияют на работу выключателя. Получены значения сил, действующих на опоры вала. Показано, что динамические усилия в опорах на (19-38)\% больще статических. Полученные значения усилий позволяют выбрать материал вала и подшипники. Библ. 19, рис. 12.

Ключевые слова: вакуумные выключатели, механические напряжения, деформация вала.

Introduction. In the past 10-15 years a dominant position on the market of medium voltage (MV) circuit breakers, vacuum circuit breakers have taken in which as a drive bistable electromagnetic actuators with highcoercive permanent magnets are used. The leader in this area is the concern ABB, the first provided such a circuit breaker (VM1) in 1990 [1]. In Ukraine, these circuit breakers are manufactured by CJSC «High Voltage Union» and «AVM AMPERE» [2]. In the circuit breakers BB-TEL («Tavrida Electric» [3]) the electromagnetic actuators with low-coercive permanent magnets are used. Vacuum circuit breakers with electromagnetic actuators are characterized by simplicity of design, high reliability and they do not require preventive maintenance for many years.

At the Department for Electrical Apparatus, NTU «KhPI» for more than 10 years works are underway related to research, improvement and development of new configurations of vacuum circuit breakers and MV contactors [4-7]. One of the directions of such works is investigation of mechanical processes in circuit breakers with vertical (relative to the drive module) poles with vacuum interrupters. The design of these circuit breakers provides transfer of motion from the actuator to the movable contacts through the drive shaft (Fig. 1) the actuator through the axis 3 rotates the shaft which axes 4 are connected to the movable contacts through traction insulators.

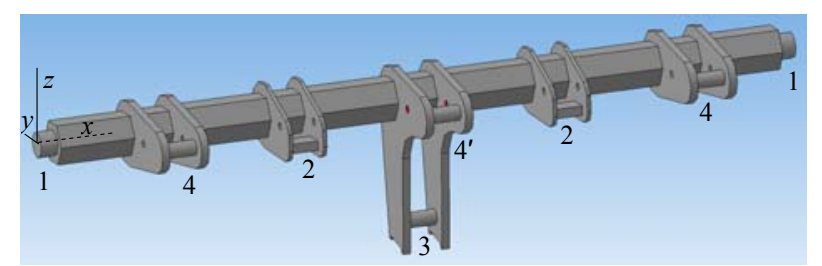

Fig. 1. Circuit breaker's drive shaft, where 1 - shaft mount axes in bearings; 2 - planes of force application of OFF springs;

3 - electromagnetic actuator's rod mounting axis; $4,4^{\prime}$ - moving contacts' rod mounting axes in the end and medium poles; $x, y, z$-coordinate system axes

Problem definition. During investigation of the circuit breaker drive operation on research prototypes the following have been founded:

- on the shaft which is mounted in two bearings without intermediate supports, significant load are applied so the shaft is deformed, and the failure of contacts and forces of their preload decrease (relative forces calculated for a absolutely rigid shaft);

- shaft deformation has complex nature (bending and twisting) and as a result in bearings there are not only radial but also axial forces;

- shaft torsional vibrations arising in dynamic modes affect the course and contacts preload.

In this regard, it has been defined range of questions, the answers to which lead to an understanding of 
directions of design of such devices, namely: 1) whether the critical is reduction of the forces of contact pressure due to deformation of the shaft? 2) whether the contact bounces at vibrations of the shaft are possible? 3) how critical are axial forces in the bearings? 4) how the course and preload of the contacts at they wear do change?

The aims and goal. The aim of the work is to create a mathematical model to calculate the forces and deformations of the drive shaft in static and dynamic modes, in order to determine the effect of these parameters on the operation of the vacuum circuit breaker of the configuration under consideration, which could serve as the basis for making recommendations for the design of devices of this type.

Despite the fact that in the literature the shafts calculation is widely presented ([8-11] show the most basic research), the problem is that the calculations of shafts of such a design under such conditions of mounting (Fig. 1) are absent. As shown in [12], calculations of complex structures can be carried out only by numerical methods, so all calculations in this paper were carried out in the COMSOL package by the finite element method.

The 3D model of the shaft (Fig. 1) has been created in the AutoCAD environment, and then exported to the COMSOL environment.

The calculation of the circuit breaker shaft of the accepted model. As an example, here is an example of calculation of the shaft of the experimental MV vacuum circuit breaker. Initial data: steel shaft length - $574 \mathrm{~mm}$; sectional shape - hexagon with inscribed circle diameter of $32 \mathrm{~mm}$; the ratio of actuator axis stroke and traction insulators axes -1.5 ; total force of OFF springs (acting on the surface 2 of Fig. 1) $-1000 \mathrm{~N}$; the total force of the initial compression of the contact springs (applied to the axes 4 of Fig. 1) $-6600 \mathrm{~N}$ (2200 N per pole); move of the axis 3 (Fig. 1) of the actuator after the contacts touch $6 \mathrm{~mm}$; theoretical course of traction insulators axes after touching the contacts (failure of contacts at absolutely rigid shaft, the axes 4 of Fig. 1) $-3.92 \mathrm{~mm}$, by the far point of the axes diameter - $4.3 \mathrm{~mm}$; contact spring stiffness $-280 \mathrm{kN} / \mathrm{m}$; the total reaction force of the contact springs at the absolutely rigid shaft (applied to the axes 4 of Fig. 1) in the final position of the shaft $-9900 \mathrm{~N}$ (3300 N per pole).

The assumptions adopted in the calculation: mounting of the shaft supports are rigid; shaft ends rest on the non-deformable bearings; OFF springs stiffness is not taken into account (by order of magnitude less than the rigidity of the contact springs). The boundary conditions: displacement of the axis 3 in the direction minus $y$ (Fig. 1) in the range $0 \mathrm{~mm} \ldots 6 \mathrm{~mm}$ is given; on planes 2 (Fig. 1) specific values of OFF spring forces are given; on the axes 4 specific values of the forces of contact springs with regard to their preload are given; on the surfaces 1 and the ends of the shaft conditions $\vec{\Delta} \cdot \vec{n}=0$ are given(where $\vec{\Delta}$ is the displacement vector, $\vec{n}-$ is the normal to the surface). The last condition ensures rotation of the shaft about its longitudinal axis $x$ without friction and without axial movement.
The calculation results in statics. Due to the deformation of the shaft (Fig. 2) the values of stroke of contacts rods and forces of contact pressure as compared with the calculation results at absolutely rigid shaft change. Appropriate calculated dependences are shown in Fig. 3.

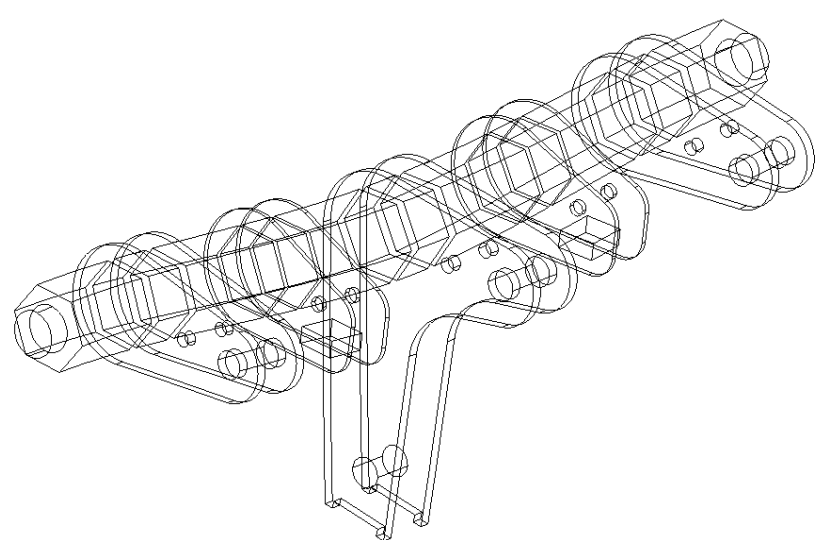

Fig. 2. Shaft deformation at 20 times magnification

As it follows from Fig. 3, a, in the final position of the travel distance is less than at the absolutely rigid shaft at $1.05 \mathrm{~mm}$ for medium pole and at $1.3 \mathrm{~mm}$ for the outer poles. This reduction in travel causes the reduction in contact pressure forces (Fig. 3,b). In particular, the initial pressing is reduced compared with pressing for the nondeformable shaft to $140 \mathrm{~N}$, final for the extreme pole - to $340 \mathrm{~N}$ for the medium - to $280 \mathrm{~N}$ which is $10 \% \ldots 11 \%$ of the contact pressure and has little effect on the circuit breaker operation.

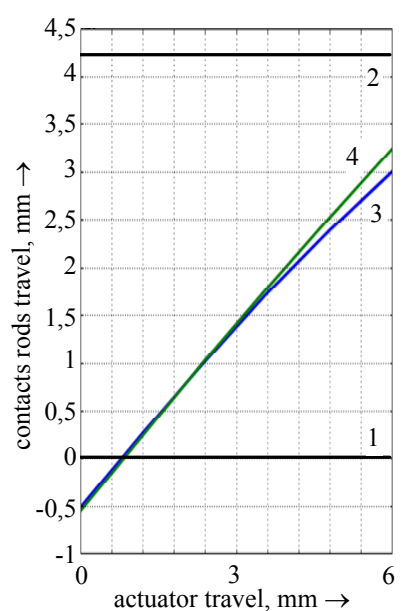

a)

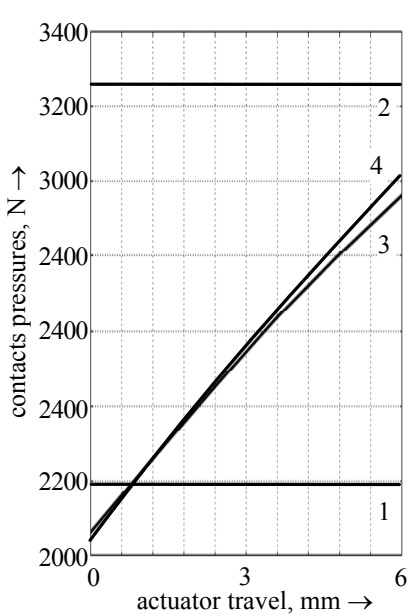

b)
Fig. 3. Dependencies of contacts rods travel $(a)$ and contact pressure $(b)$ as a function of the actuator travel: 1 - the initial value for the rigid shaft (contact touch); 2 - the final value at the absolutely rigid shaft; 3 - the calculated value in the end pole; 4 - the estimated value in the medium pole

One of the important calculated parameters are the values of the forces acting on the shaft from the circuit breaker housing or forces acting on the bearings (final values are presented at the maximum travel). As a result of calculations, the values of forces by the coordinates are obtained (Fig. 1): $R_{x}=3428 \mathrm{~N}, R_{y}=5275 \mathrm{~N}, R_{z}=4969 \mathrm{~N}$. 
Longitudinal force $R_{x}$ arises from the shaft ends stop to the bearings and bending of the shaft. This radial force will be equal to:

$$
F_{r}=\sqrt{R_{z}^{2}+R_{y}^{2}}=7245 \mathrm{~N} .
$$

Obtained values make it possible to evaluate the operating conditions of bearings and choose their sizes. Design load corresponds, for example, 6304-2RSH-SKF bearing (Sweden) with dimensions $20 \times 52 \times 15$ with acceptable loads: dynamic $-15.9 \mathrm{kN}$ and static $-7.8 \mathrm{kN}$. It is supposed that the permissible axial force reaches $70 \%$ of the radial load unused. Consequently, the permissible axial load is $(15900-7245) \cdot 0.7=8655 \mathrm{~N}$. Thus, both radial and axial loads are less than the allowable value found.

The calculation results in dynamics. Static analysis does not provide complete information about the stresses, displacements and acting operating forces. This is associated with considerable force, speed and the moving masses in the process of the circuit breaker operation. Therefore, it is necessary to take into account the dynamics of the circuit breaker operation.

Accounting of traction insulators masses. The masses of moving traction insulators attached to axes 4 (Fig. 1) are taken into account by the increase in the density of the axes materials according to the formula:

$$
m=\rho \cdot V,
$$

where $m$ is the known mass of the traction insulator equal to $0.725 \mathrm{~kg} ; \rho$ is the unknown material density; $V$ is the known volume of the one axis 4 .

In the considered example, the density value was found to be $2.56 \cdot 10^{5} \mathrm{~kg} / \mathrm{m}^{3}$.

Determination of the damping coefficients. In transient analysis it is necessary to take into account the damping parameters that determine the power losses in the system (damping of vibrations of the system).

Damping by Rayleigh [13] suggests a method of accounting damping parameters depending on the mass of moving bodies and the rigidity of the system and includes the definition of the parameters of the diagonal matrix of stiffness or damping:

$$
C_{i}=\alpha(M)+\beta(K) \cdot \omega_{i}^{2}
$$

where $C_{i}$ is the stiffness matrix; $\alpha(M)$ is the attenuation coefficient depending on the mass $M$ of the body; $\beta(K)$ is the attenuation coefficient depending on the system rigidity $K ; \omega_{i}=2 \cdot \pi \cdot f_{i}$ is the angular frequency of the $i$-th mode; $f_{i}$ is the corresponding frequency of the $i$-th mode.

Rigidity of the $i$-th mode can be represented as

$$
C_{i}=2 \cdot \xi_{i} \cdot \omega_{i},
$$

there $\xi_{i}$ is the viscous damping coefficient.

If damping coefficients for the $i$-th and $j$-th modes are known, the coefficients $\alpha(M)$ and $\beta(K)$ are determined by the expression:

$$
\frac{1}{2} \cdot\left|\begin{array}{cc}
\frac{1}{\omega_{i}} & \omega_{i} \\
\frac{1}{\omega_{j}} & \omega_{j}
\end{array}\right| \cdot\left|\begin{array}{c}
\alpha(M) \\
\beta(K)
\end{array}\right|=\left|\begin{array}{l}
\xi_{i} \\
\xi_{j}
\end{array}\right| .
$$

For steel the losses factor $\eta=0.2$ is known [14]. Then, assuming that $\xi_{i}=\xi_{j}$ and taking into account that $\xi=\eta / 2$, we obtain

$$
\xi_{i}=\xi_{j}=0.1
$$

and corresponding values of $\alpha(M)$ and $\beta(K)$.

Natural oscillation frequencies calculations were carried out in a special mode of the COMSOL software. Fig. 4 shows the shaft shapes for the first and the second modes (enlarged).

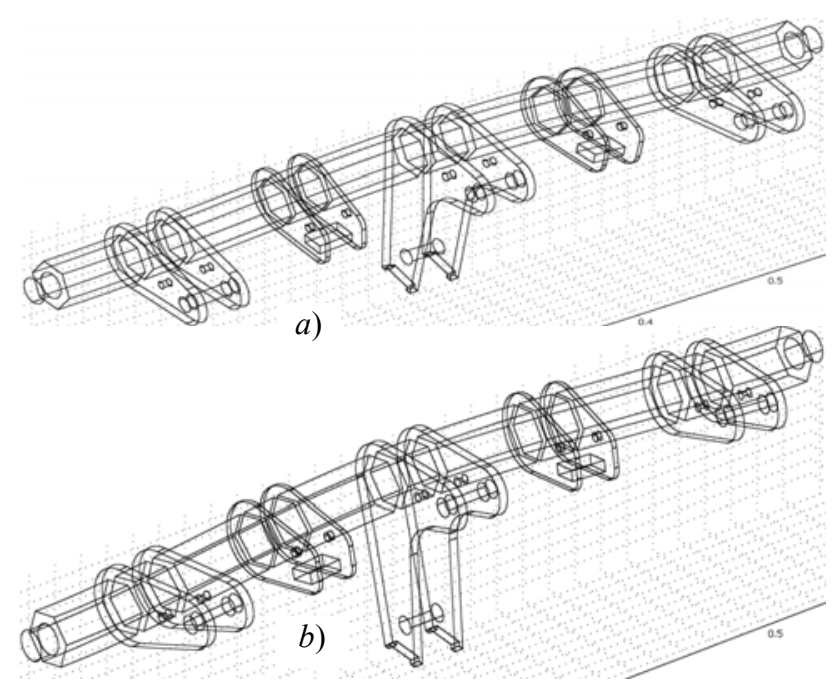

Fig. 4. Shapes of the first $(a)$ and the second $(b)$ modes of the shaft oscillations

As a result of calculations the following frequency values were obtained: $f_{1}=242.8 \mathrm{~Hz}, f_{1}=338.0 \mathrm{~Hz}$.

Based on the frequencies found, by means of (5) the coefficients of damping of the shaft oscillations were found:

$$
\alpha=177.6 \mathrm{~s}^{-1}, \beta=5.5 \cdot 10^{-5} \mathrm{~s} .
$$

Formation of the equations of motion of the electromagnet rod and initial conditions. To calculate the dynamics it is necessary to set the temporal dependence of the movement of the actuator rod within the failure of contacts. Such calculations have been carried out previously on the basis of the coupled solution of the electromagnetic field equations, the electric circuit equations and the equation of motion [15-19]. Taking into account the location of the coordinate system, approximating temporal dependence of the actuator travel will be as follows:

$$
S_{y}(t)=\left\{\begin{array}{l}
-6 \cdot 10^{-3} \cdot \sin (500 \cdot t)[m], \text { if } t<\pi / 1000 \\
-6 \cdot 10^{-3}[\mathrm{~m}], \text { if } \pi / 1000
\end{array} .\right.
$$

As the origin the circuit breaker contacts closure time after which the actuator «takes» the failure of contacts is assumed.

Initial velocity of the actuator's rod axes (item 3, Fig. 1):

$$
V_{0}=\frac{d S_{y}(0)}{d t}=-3 \mathrm{~m} / \mathrm{s} .
$$

Initial velocity of the shaft points:

$$
v_{0 i}=\vec{\omega} \times \vec{r}_{i} .
$$

In (8) we noted 


$$
\vec{\omega}=\vec{e}_{x} \cdot \frac{V_{0}}{l}, \vec{r}_{i}=\vec{e}_{y} \cdot y+\vec{e}_{z} \cdot z,
$$

where $l$ is the distance from the shaft axis of rotation to the actuator's rod mounting axis 3 (Fig. 1); $\vec{r}_{i}$ is the distance from points belonging to the shaft to its longitudinal axis $x$.

The calculation results at the initial values of the force and travel of pressure of contacts. Diagrams of temporal dependencies of contacts rods axes travel (item 4, Fig. 1) are shown in Fig. 5.

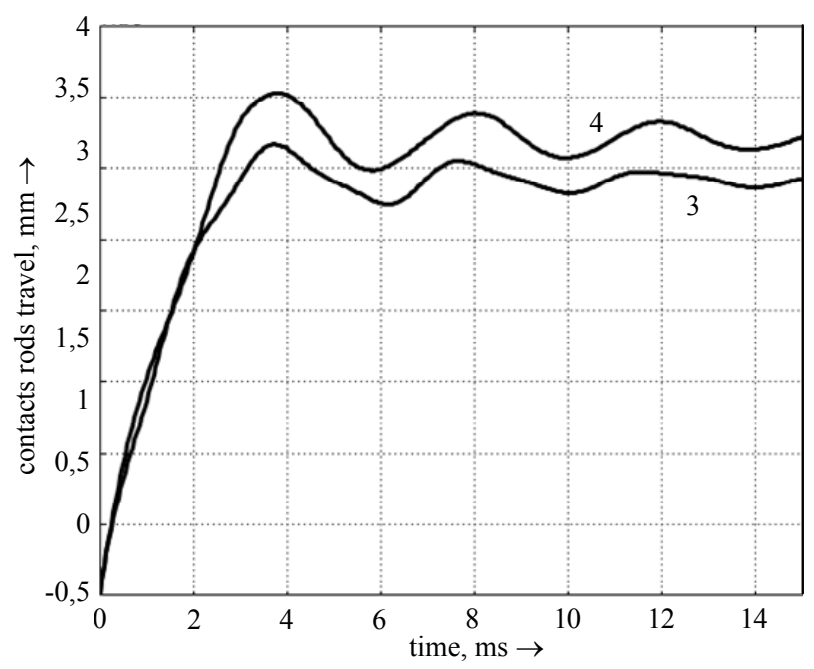

Fig. 5. Temporal dependencies of contacts rod axes travel: 3 - travel calculated value in the end pole; 4 - travel calculated value in the medium pole

From Fig. 5 it is seen that the movement of the axes of contact rods is oscillatory in nature, however, these oscillations are not critical, as their scope is relatively small (the largest value is approximately $0.25 \mathrm{~mm}$ which is much less of the pressure travel - about $4 \mathrm{~mm}$ ) and does not result in the opening of contacts. Obviously, the same oscillations and forces contact pressure will be exposed (Fig. 6).

From Fig. 6 it follows that the final values of the forces tend to their values in statics $-2961 \mathrm{~N}$ and $3016 \mathrm{~N}$, and the force of the initial pressing (in contrast to the situation in statics) at the moment of contact closure does not reduce due to the inertia of the shaft and other connected design elements.

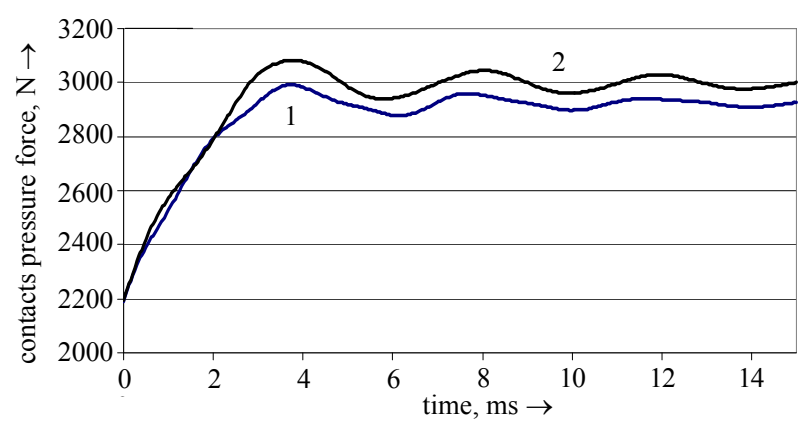

Fig. 6. Oscillation of the contact pressure force at the end (1) and medium (2) poles

Fig. 7 shows the total force of contact pressure as a function of time.

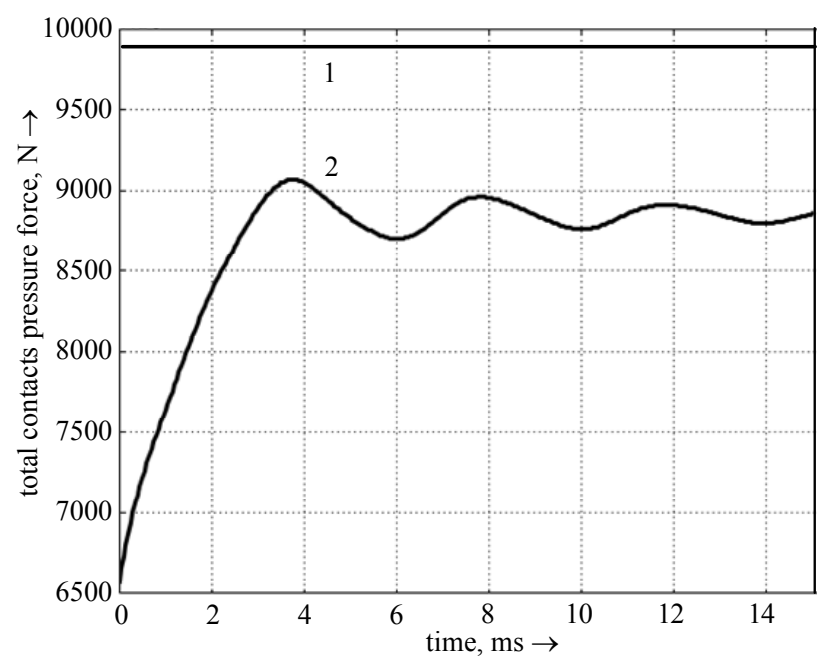

Fig. 7. Total force of contact pressure at absolutely rigid shaft (1) and calculated force (2)

In the final position after the end of the transient, the difference between the pressure at the absolutely rigid shaft and the calculated values is $9893-8927=966 \mathrm{~N}$ which is of the order of $10 \%$ of the theoretical and is not critical.

Dynamic values of bearing reactions are of some interest (Fig. 8).

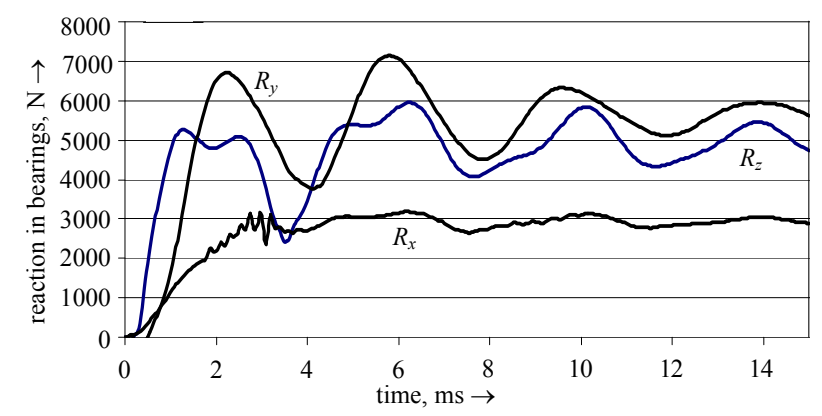

Fig. 8. Dynamic reactions of forces in bearings by coordinate axes

As follows from the Figure, the maximum dynamic responses over the static reaction on the axes: $x-1.38$ times; $y-1.35$ times; $z-1.19$ times. Fig. 9 shows the graph of the radial dynamic force.

Calculations show that the value of the axial force does not exceed the permissible value. Fig. 10 shows the permissible axle force on the axle and axial force of the bearing. The Figure shows that the dynamic axial force does not exceed the permissible value.

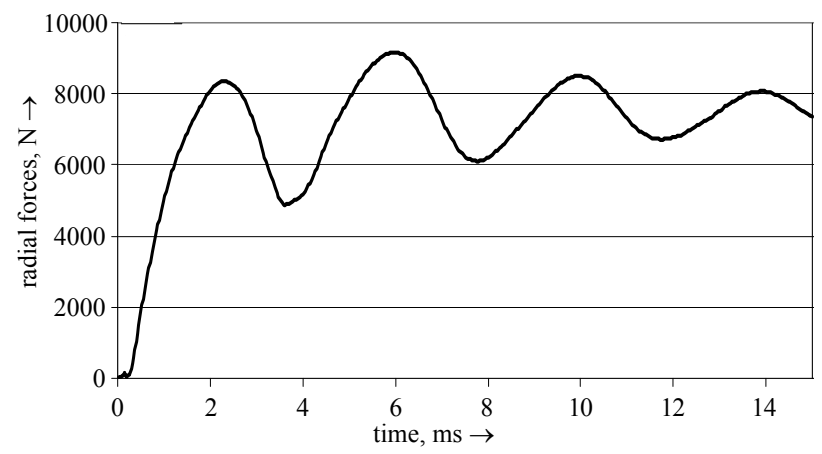

Fig. 9. Radial forces in the bearing 


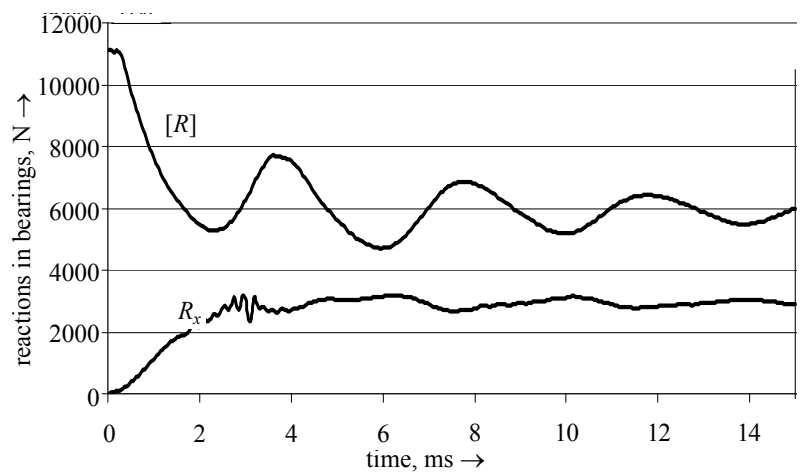

Fig. 10. Temporal dependencies of the axial $R_{x}$ and permissible axial $[R]$ forces on the bearing

The calculation results in the case of halving compression travel of the contacts at their wear (maximum contact wear during operation). In the process of operation of the circuit breaker as a result of the contact wear value of the failure of contacts reduces which affects the operation of the circuit breaker. Calculation results with decreasing contact failure twice (maximum contact wear) are presented below.

The final value of the contact pressure force decreases: on the end poles from $2961 \mathrm{~N}$ to $2545 \mathrm{~N}$; on the medium pole - from $3016 \mathrm{~N}$ to $2550 \mathrm{~N}$ as compared with the values for new contacts. Bearings reaction here also changes: $R_{x}$-from $2428 \mathrm{~N}$ to $782 \mathrm{~N} ; R_{y}-$ from $5275 \mathrm{~N}$ to $3164 \mathrm{~N} ; R_{z}-$ from $4969 \mathrm{~N}$ to $4320 \mathrm{~N}$.

Fig. 11 shows graphs of temporal dependencies of contacts rods axes travel (item 4 in Fig. 1) at reduced course of the compression.

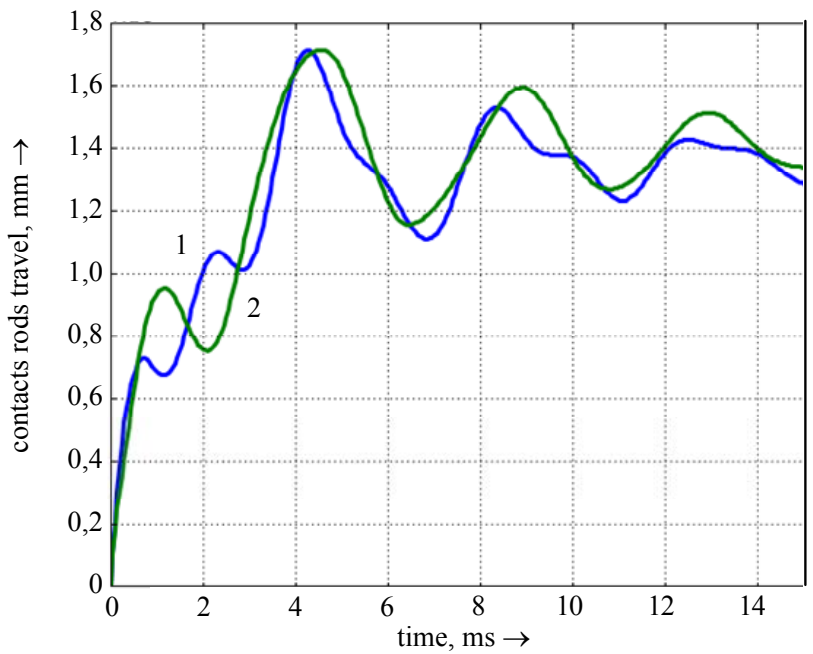

Fig. 11. Contacts rods axes travel in time:

1 - calculation value of the travel in the end pole;

2 - calculation value of the travel in the medium pole

The graphs shown in Fig. 11 demonstrate that the contact wear leads to a certain increase in the swing of oscillations of the contacts rods axes stroke - the maximum amplitude value increases to $0.3 \mathrm{~mm}$ which is far less even halved pressure stroke - to $2 \mathrm{~mm}$, so here the contact opening does not occur.

Fig. 12 shows the calculated graph of the changes in the dynamics of the forces of contact pressure only at the end poles of the circuit breaker (as at the medium pole the pushing force is more) at reduced pressure stroke. As we can see, the force of contact pressure does not drop below the critical value $-2000 \mathrm{~N}$.

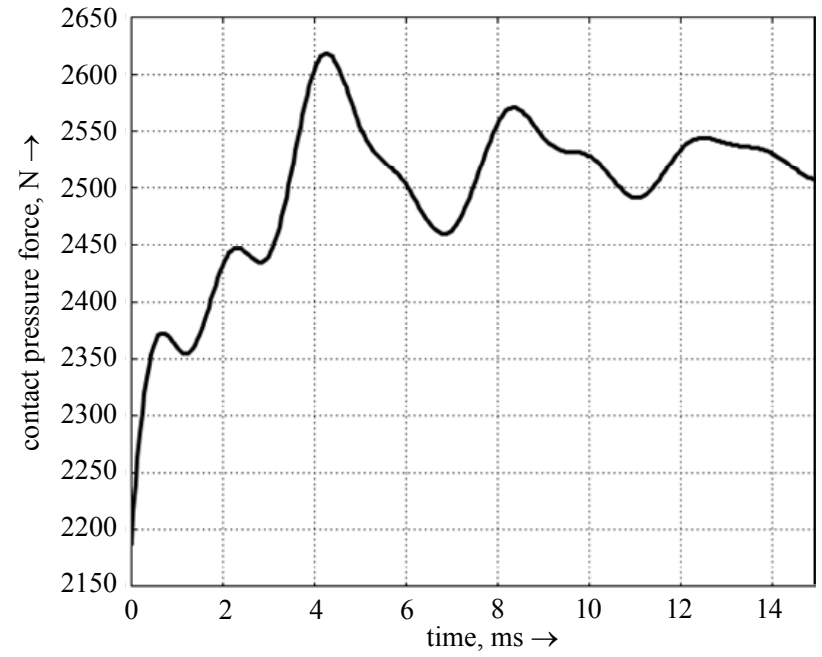

Fig. 12. Oscillations of the contact pressure force at the end poles at halving pressure stroke

In order to verify the adopted calculation assumption of the stiffness of the circuit breaker housing, calculation of its deformation in the stationary mode taking into account the effect on it of respective stationary forces $R_{x}$, $R_{y}, R_{z}$ provided rigidly fixing of the lower surface is carried out. Because of the symmetry of the structure, calculation of the half of the housing was carried out with the corresponding boundary condition on the plane of symmetry. The calculation results show that the maximum deformation of the housing is observed in the plane of symmetry (middle) in its upper part and is equal to $7.2 \cdot 10^{-5} \mathrm{~m}$ which is much less that shaft deformation.

\section{Conclusions.}

1. During the operation the shaft is exposed essential deformations due to which because of the reduction of the pressure stroke, contact force decreases by $10 \% \ldots 11 \%$ in comparison with the calculated values provided undeformable shaft. Such a reduction is not critical and slightly affects the operation of the circuit breaker.

2. Oscillations of contacts rods axes and contact pressure forces, taking into account the shaft deformations in dynamics, do not lead to contacts bouncing at $\mathrm{ON}$ operation.

3. Complicated shaft deformation leads to the appearance of the axial forces.

4. Dynamic forces in the bearings are by $19 \% \ldots 38 \%$ more than static ones, which should be considered at selecting bearings.

5. At the contact wear the contacts rods travel and contact pressure reduce: at double decreasing the pressure stroke - for $466 \mathrm{~N}$ in the medium pole and for $416 \mathrm{~N}$ in the end poles. However, the reduced force (about $2550 \mathrm{~N}$ per pole) ensures normal operation of the circuit breaker.

6. In the case of the maximum contact wear (reduction in pressure stroke twice), the dynamic vibrations of the system do not lead to bouncing (vibration) of contacts.

7. To reduce the shaft deformations it is necessary that end shaft surfaces should stop on the bearings, and the 
bearings must be mounted rigidly in the housing which increases the rigidity of the entire system.

8. On the basis of the calculations as the material of the shaft we can recommend steel 30 hardened with $\sigma_{\mathrm{B}}=11 \cdot 10^{8} \mathrm{~N} / \mathrm{m}^{2}$ or another steel with similar characteristics.

\section{REFERENCES}

1. VM1. Medium voltage vacuum circuit-breaker with magnetic actuator Available at: https://library.e.abb.com/public/5800cc5773e0b321c12575d000 4d7342/LE VM1(EN)B 1VCP000185-0904x.pdf (accessed 03 October 2016).

2. Modernizirovannyi vakuumnyi vykliuchatel's elektromagnitnym aktuatorom (Modernized vacuum pole breaker with magnetic actuator). Available at: http://www.nbuv.gov.ua/old_jrn/Natural/eie/2011_3/22.pdf/ (accessed 11 December 2014). (Rus).

3. Vakuumnye vykliuchateli 6-20 kV (Vacuum circuit-breakers 6-20 $\mathrm{kV}$ ). Available at: http://www.tavrida.com/ter/solutions/VCB/ (accessed 09 October 2016). (Rus).

4. Klymenko B.V., Bugaychuk V.M., Grechko A.M. Electromagnetic actuators for MV vacuum circuit-breakers. Bulletin of NTU «KhPI», 2004, no.42, pp. 73-80. (Rus).

5. Klymenko B.V., Grechko A.M., Bugaychuk V.M. Prototype two-position solenoid actuator for MV vacuum circuit-breaker. Electrical engineering \& electromechanics, 2005, no.2, pp. 2328. (Rus). doi: 10.20998/2074-272X.2005.2.06.

6. Klymenko B.V., Grechko A.M., Bugaychuk V.M., Vyrovets S.V. A fast electromagnetic drive for an average-voltage vacuum switch with ousting of magnetic field. Electrical engineering \& electromechanics, 2006, no.4, pp. 22-26. (Rus). doi: 10.20998/2074-272X.2006.4.03.

7. Klymenko B.V., Grechko A.M., Eres'ko A.V. An electromagnetic drive with a twoposition magnetic catch for medium-voltage vacuum circuit breakers. Electrical engineering \& electromechanics, 2007, no.6, pp. 40-43. (Rus). doi: 10.20998/2074-272X.2007.6.08.

8. Birger I.A. Raschet na prochnost' detalei mashin [Calculation of the strength of machine parts]. Moscow. Mashinostroenie Publ., 1993. 639 p. (Rus).

9. Maslov G.S. Raschety kolebanii valov: spravochnik [Calculations shaft vibrations: Handbook] Moscow. Mashinostroenie Publ., 1980. 151 p. (Rus).

10. Ponomarev S.D. Raschety na prochnost' $v$ mashinostroenii. T.3 [Calculations of strength in mechanical engineering. Vol.3]. Moscow, Mashgiz Publ., 1959. 1118 p. (Rus).
11. Groman M.B., Kogaev V.P., Shneiderovich R.M. Valy i osi. Konstruirovanie $i$ raschet [Shafts and axis. Design and calculation]. Moscow, Mashinostroenie Publ., 1970. 320 p. (Rus).

12. Zenkevich O. Metod konechnykh elementov $v$ tekhnike [FEM in the techniques]. Moscow, Mir Publ., 1975. 541 p. (Rus).

13. Available at:

http://help.solidworks.com/2013/russian/solidworks/cworks/c ra yleigh damping.htm (accessed 05 November 2016).

14. Available at:

https://syont.files.wordpress.com/2007/05/damping-propertiesof-materials.pdf (accessed 02 November 2016).

15. Baida E.I. Electromagnetic equations based calculation of transients in an electromechanical mechanism. Electrical engineering \& electromechanics, 2008, no.5, pp. 39-43. (Rus). doi: 10.20998/2074-272X.2008.5.09.

16. Baida E.I. Modeling of dynamic characteristics of DC electromagnetic mechanisms with a magnetic latch. Electrical engineering \& electromechanics, 2010, no.2, pp. 3-5. (Rus). doi: 10.20998/2074-272X.2010.2.01.

17. Baida E.I. Calculation of dynamics twoposition electromagnet of direct-current with magnetic catch. Electrical engineering \& electromechanics, 2010, no.4, pp. 10-12. (Rus). doi: 10.20998/2074-272X.2010.4.02.

18. Baida E.I. Influence of additional resistance on pre-start time of two-position electromagnetic drive with magnetic latch for MV vacuum circuit-breaker. Electrical engineering \& electromechanics, 2011, no.4, pp. 13-15. (Rus). doi: 10.20998/2074-272X.2011.4.03.

19. Baida E.I. A mathematical model for calculating the dynamics of two-position electromagnetic actuator vacuum circuit breakers medium voltage. Journal of scientific publications graduate and doctoral students, 2013, no.1, pp. 136-141. (Rus).

Received 30.11.2016

E.I. Baida ${ }^{1}$, Candidate of Technical Science, Associate Professor,

B.V. Klymenko ${ }^{1}$, Doctor of Technical Science, Professor,

${ }^{1}$ National Technical University «Kharkiv Polytechnic Institute»,

2, Kyrpychova Str., Kharkiv, 61002, Ukraine,

phone +380961877707, +380506534982

e-mail: baida.kpi@gmail.com, b.v.klymenko@gmail.com

How to cite this article:

Baida E.I., Klymenko B.V. Investigation of mechanical stresses in the drive shaft of MV vacuum circuit breaker. Electrical engineering \& electromechanics, 2017, no.1, pp. 10-15. doi: 10.20998/2074-272X.2017.1.02. 